\title{
Creation of Geographical Information System for Highways of Kvemo Kartli (Georgia)
}

\author{
Mariam Elizbarashvili ${ }^{1}$, Bela Kvirkvelia ${ }^{1}$, Shalva Elizbarashvili ${ }^{2}$, \\ Tamar Khuntselia ${ }^{1}$, Marina Tatanashvili ${ }^{1}$, Maia Kimeridze ${ }^{1}$ \\ ${ }^{1}$ Ivane Javakhishvili Tbilisi State University \\ Ilia Tchavtchavadze Avenue 1, \\ Academic Building I, 0179 Tbilisi, Georgia \\ mariam.elizbarashvili@tsu.ge; bela.kvirkvelia@tsu.ge; \\ shalvaeliz1@gmail.com; takokhuntselia@gmail.com; marinamarina79@ymail.com; \\ maikokimeridze@yahoo.com \\ ${ }^{2}$ Institute of Hydrometeorology of Georgian Technical University \\ D.Agmashenebeli Avenue. 150a, 0112 Tbilisi, Georgia
}

\section{Extended Abstract}

Kvemo Kartli is one of the most important administrative regions of Georgia. Its northern and western borders run along the Trialeti and Samsari ridges, bordering the republics of Azerbaijan and Armenia to the south. It is bordered to the north by the capital of Georgia Tbilisi and supplies the city with agricultural products. The administrative region includes one city of regional subordination (Rustavi) and six municipalities: Tsalka, Tetritskaro, Marneuli, Dmanisi, Gardabani and Bolnisi, its area is $6,528 \mathrm{sq}$. Km. which is $10 \%$ of the total area of Georgia. The environment in the region is diverse and mountainous. The population is multinational and accounts for 432,300 people, constituting $11.42 \%$ of the whole population of Georgia.

Highways are one of the most important components of critical infrastructure of the region. Through the road network, the population carries out agricultural production, has access to medical services, educational institutions, tourist resorts, etc. Therefore, an orderly and well-maintained highway network is necessary for the socio-economic development of the region. Bad road conditions lead to the threat of improper control of the regions, depopulation of the villages, lack of access to vital services, the insufficient use of tourism potential, etc. The total length of roads in the region (including internal settlement roads) is $3036 \mathrm{~km}$. Three highways of international importance pass through the territory of Kvemo Kartli: Tbilisi-Red Bridge (towards the border with Azerbaijan), Tbilisi-Marneuli-Guguti and Marneuli-Sadakhlo (towards the border with Armenia). The total length of roads of international importance is $229.2 \mathrm{~km}$. Most of the domestic roads of small and local importance (including the roads connecting the municipal centers and the respective settlements) are not covered with asphalt or concrete.

This report presents the results of the created geographic information system for the regional road network. Theoretical and cartographic materials were collected to form the basis of the Geographic information system (GIS) for road network, bridges, health infrastructure; two field expeditions were organized and orthophotos, space images and topographic maps were digitized. The geographical information system that includes and integrates data on the road network of Kvemo Kartli Region, bridges, healthcare infrastructure (primary, secondary and tertiary healthcare facilities, ambulance service, pharmacies), and the population was developed. The geographic information system created by us differs from the existing one in scale (1:10000 scale) and specific detailed information regarding the medical centers (first, second and third level health facilities), emergency services, pharmacy network, road infrastructure, population and public transport, road surface, off-road, speed limit, traffic type, etc., all the information was verified and updated during the fieldwork.

This work was supported by Shota Rustaveli National Science Foundation of Georgia (SRNSFG) № FR-19-14993. 